\title{
Metformin exhibits the anti-proliferation and anti-invasion effects in hepatocellular carcinoma cells after insufficient radiofrequency ablation
}

\author{
Qingyun Zhang ${ }^{1,2+}$, Jian Kong ${ }^{1+}$, Shuying Dong ${ }^{1}$, Wenlei $\mathrm{Xu}^{1}$ and Wenbing Sun ${ }^{1 *}$ (B)
}

\begin{abstract}
Background: The mechanisms and prevention of progression of hepatocellular carcinoma (HCC) after insufficient radiofrequency ablation (RFA) has been preliminarily investigated, therefore, new strategy needs to be investigated to prevent the process. Whether metformin could be used to inhibit the growth of HCC after insufficient RFA and further prevent the progression of residual HCC remains unclearly.

Methods: MTT assay, colony formation assay and transwell assay were used to observe the cell viability, migration and invasion. Western blot and immunohistochemistry methods were used to observe the expression of proteins. Xenograft model was used to evaluate the growth of HCC cells in vivo.
\end{abstract}

Results: Metformin inhibited the enhanced proliferation, migration and invasion of HepG2 and SMMC7721 cells after insufficient RFA (named as HepG2-H and SMMC7721-H). Metformin deregulated the expression of p-Akt in HepG2 and SMMC7721 cells after insufficient RFA through AMPK/PTEN pathway. HepG2-H cells also exhibited larger tumor size in vivo. Higher expression of Ki-67 and CD31 and lower expression of E-cadherin were observed in HepG2-H tumors. Metformin blocked the enhanced growth of HepG2 cells in vivo after insufficient RFA. Metformin had no apparent toxicity on nude mice.

Conclusions: Metfromin inhibited the growth of HCC cells after insufficient RFA, and may be used to prevent the progression of HCC after RFA.

Keywords: Hepatocellular carcinoma, Insufficient radiofrequency ablation, Metformin

\section{Background}

Hepatocellular carcinoma (HCC) is one of the most common malignancies worldwide with rising incidence in both Eastern and Western countries [1]. The treatment modalities for HCC include surgical resection, radiofrequency ablation (RFA), and liver transplantation [2]. RFA was shown to achieve comparable overall survival and better tolerability for early $\mathrm{HCC}$, and is recommended as the priority treatment for very early-stage $\mathrm{HCC}$ with

\footnotetext{
*Correspondence: klaxst@163.com

${ }^{\dagger}$ Qingyun Zhang and Jian Kong contributed equally to this work

1 Department of Hepatobiliary Surgery, Beijing Chao-yang Hospital,

Capital Medical University, Beijing 100043, China

Full list of author information is available at the end of the article
}

impaired liver functional reserve [3]. However, suboptimal RFA treatment for HCC has been reported as a risk factor of early diffuse recurrence [4].

Several researches have explored the mechanisms and prevention of progression of HCC after insufficient RFA $[5,6]$. Our previous study demonstrated that sorafenib suppressed the epithelial-mesenchymal transition of HCC after insufficient RFA. Nevertheless, sorafenib is the first and only molecular targeted therapy approved for use in advanced HCC by the U.S. Food and Drug Administration, which also causes multiple human toxicities, including use-limiting anorexia, GI bleeds and hand-foot syndrome [7]. Consequently, new strategy needs to be investigated to prevent the process. 
Metformin is recommended as first-line therapy for all newly diagnosed Type 2 Diabetes Mellitus (T2DM) patients. Some epidemiologic data have highlighted the positive effects of metformin to reduce cancer incidence and mortality [8-11]. Anticancer effects of metformin can be divided into two non-exclusive categories: an indirect effect by reducing the blood glucose and insulin levels, and a direct effect on cancer cells, partially through the activation of AMPK [12]. Metformin also showed promising prospect in the treatment of HCC. Metformin conferred risk reduction for developing HCC recurrence after resection [13]. Metformin also inhibited cell proliferation, invasion, angiogenesis, and induced apoptosis in HCC [14-17]. Metformin also enhanced the effect of sorafenib, arsenic trioxide and 5-fluorouracil, and reversed multidrug resistance of HCC [18-22]. Whether metformin could be used to inhibit the growth of HCC after insufficient RFA and further prevent the progression of residual $\mathrm{HCC}$ remains unclearly.

In the present study, we observed the effects of metformin on cell proliferation, migration and invasion of HCC cell lines (HepG2 and SMMC7721) after insufficient RFA in vitro. Furthermore, we analyzed the influences of metformin on changes of PCNA, E-cadherin, VEGF, and Akt signaling pathways involved in the process in HCC cells after insufficient RFA. We also performed in vivo experiments to study the effect of metformin on the growth of HCC cells after insufficient RFA in a BALB/c nu/nu mice model.

\section{Methods}

\section{Cell line and cell culture}

The human HCC cell line (HepG2 and SMMC7721) was obtained from the American Type Culture Collection (ATCC; Manassas, VA, USA). Cells were cultured in high-glucose Dulbecco's modified Eagle medium (DMEM) supplement with 10\% fetal bovine serum (FBS), $100 \mathrm{U} / \mathrm{ml}$ penicillin and $100 \mu \mathrm{g} / \mathrm{ml}$ streptomycin in humidified atmosphere of $5 \% \mathrm{CO}_{2}$ at $37^{\circ} \mathrm{C}$.

\section{Reagents and antibodies}

Metformin was obtained from Sigma-Aldrich (St. Louis, MO, USA). Horseradish peroxidase (HRP)-labeled antimouse and anti-rabbit secondary antibodies were from Santa Cruz (Dallas, TX, USA). Phospho-anti-Akt, PTEN and phospho-anti-AMPK antibodies were purchased form Cell signaling (Beverly, CA, USA). Anti-Ecadherin, VEGF, PCNA, t-Akt, t-AMPK and $\beta$-actin were bought form Abcam (Cambridge, TX, USA).

\section{Insufficient RFA in vitro}

Insufficient RFA was simulated in vitro as described before [23]. Simply, HCC cells were seeded into the 6-well plates $\left(5 \times 10^{4}\right.$ cells/well $)$. After $24 \mathrm{~h}$, the plates were sealed and submerged in a water bath set to $47^{\circ} \mathrm{C}$ for $5 \mathrm{~min}$. Thereafter, cells were allowed to recover, and when the surviving populations reached $80 \%$ confluence, cells were propagated into the 6-well plates and exposed to above treatment for $10 \mathrm{~min}$. Then the process was repeated and cells were sequentially exposed to above treatment for 15, 20 and $25 \mathrm{~min}$. Cells surviving from the treatment were designated as HepG2-H and SMMC7721-H cells.

\section{MTT}

Hepatocellular carcinoma cells were trypsinized and seeded into 96-well plates at a density of approximately 3000 cells per well. Twenty-four hours later, adherent cells were treated metfromin. After $72 \mathrm{~h}$ incubation, MTT reagent was added to the cells $(0.5 \mathrm{mg} / \mathrm{ml})$, and cells were then incubated for $4 \mathrm{~h}$ at $37^{\circ} \mathrm{C}$. The cells media were removed and $150 \mu \mathrm{l}$ DMSO were added to each well followed by gentle shaking of the plates to dissolve the formazan crystals. The optical density (OD) was then measured using an automated ELISA plate reader at $570 \mathrm{~nm}$.

\section{Colony formation assay}

Briefly, HepG2, HepG2-H, SMMC7721 and SMMC7721-H cells were recultured in 6-well plates (1000 cell per well), incubated with or without metformin for $24 \mathrm{~h}$, and continuously grew in complete medium for 2 weeks. Then, the cell colonies were washed with PBS, fixed by methanol, and stained with crystal violet (Beyotime, Nantong, China). The colonies were counted and compared with untreated cells.

\section{Transwell assay}

Cell migration assays were operated by a modified Boyden chamber (Costar-Corning, New York, USA). HCC cells (5000 cells per well) were added into the upper chamber, and $500 \mu \mathrm{l}$ DMEM with 10\% FBS were added into the lower chamber. After $30 \mathrm{~min}$ incubation, metformin were added to the upper chamber. The chambers were incubated under the usual culture conditions for $24 \mathrm{~h}$. After removing the filter inserts and the cells on the upper side of the filter, the migrated cells on the lower chamber were fixed with methanol, stained with crystal violet for $30 \mathrm{~min}$, washed with $\mathrm{PBS}$, and captured using photographed under an inverted fluorescence microscope (Olympus IX51) equipped with an Olympus Qcolor 3 digital camera (Olympus). Migration was assessed by counting the number of stained cells from 10 random fields at $200 \times$ magnification.

For cell invasion assay by transwell assay, each insert needed was precoated with Matrigel. The others steps were similar to cell migration assay. 


\section{Western blot}

Cells were collected and cell lysis was performed by using RIPA lysis buffer including proteased inhibitors on ice. The extracted protein was quantified by bicinchoninic acid quantification assay. Then, the total cellular proteins were subjected to SDS-PAGE gel and transferred to nitrocellulose membranes. The membranes were blocked with 5\% non-fat milk for $2 \mathrm{~h}$ and then incubated with respective primary antibody overnight at $4{ }^{\circ} \mathrm{C}$. Following washing three times with TBS-T for $10 \mathrm{~min}$, the membranes were incubated with the appropriate HRP-conjugated secondary antibody for $1.5 \mathrm{~h}$ at room temperature. The bands were captured with SuperSignal West Pico substrate (Thermo scientific, Rockford, IL, USA).

\section{Xenograft model}

Pathogen-free male BALB/c nu/nu mice (4-6 weeks of age) were obtained from Vital River Laboratories (Beijing, China). HepG2 and HepG2-H cells $\left(5 \times 10^{6}\right)$ were suspended in $200 \mu \mathrm{l}$ serum-free DMEM and matrigel (1:1) and then injected subcutaneously into the upper right flank region of 20 nude mice. After $1 \mathrm{w}$, mice were treated with metformin by oral route $(200 \mathrm{mg} / \mathrm{kg} /$ day $)$, or PBS as control every day for up to the 24th day. Tumor size was evaluated with calipers every 3 days. Mice were euthanized, and tissues were removed for fixation in the $4 \%$ paraformaldehyde for histologic examination and immunohistochemical staining.

\section{Immunocytochemistry}

Tumor specimens were immediately removed from sacrificed mice and prepared for immunohistological examination. Tumors were fixed in $4 \%$ paraformaldehyde overnight, embedded in paraffin and sectioned to a $6 \mu \mathrm{m}$ sections thickness. Tumor sections were deparaffinized via immersion in xylene, dehydrated in a graded series of ethanol, and washed with distilled water. Thereafter, tumor sections were boiled in at $92{ }^{\circ} \mathrm{C}$ in EDTA (10 mmol/l, $\mathrm{pH} \mathrm{8.0)}$ for $10 \mathrm{~min}$ and cooled at room temperature. To inhibit endogenous peroxidase activity, tumor sections were incubated with $0.3 \%$ hydrogen peroxide for $12 \mathrm{~min}$. Tumor sections were then blocked with $5 \%$ goat serum for $60 \mathrm{~min}$ at $37{ }^{\circ} \mathrm{C}$, and then incubated overnight with primary antibodies at $4{ }^{\circ} \mathrm{C}$. Tumor sections were probed with peroxidase-conjugated secondary antibodies and incubated with DAB until the desired stain intensity developed. Finally, the slides were counterstained with hematoxylin and mounted. The slides were examined with Nikon Eclipse Ti microscope under a $200 \times$ objective.

\section{Statistical analysis}

All values are expressed as the mean \pm SEM. The data were analyzed using Student's t test or the ANOVA test. A P value of $<0.05$ was considered statistically significant. GraphPad Prism (GraphPad Software Inc., San Diego, California, USA) was used for these analyses.

\section{Results}

Metformin suppressed the insufficient RFA-induced proliferation, migration and invasion of HCC cells in vitro

Our previous study demonstrated that insufficient RFA promoted proliferation, migration and invasion of HepG2 cells, therefore, we next explored whether metformin could abrogate the process. As the same in our previous study, HepG2 cells after insufficient RFA in vitro (named as HepG2-H) showed higher proliferation rate compared with HepG2 cells at 72 h (Fig. 1a). Metformin impeded the proliferation rate of HepG2 and HepG2-H cells in a dose-dependent manner (Fig. 1a). Metformin (5, 10 and $20 \mu \mathrm{M})$ abrogated the distinction of proliferation rate between HepG2 and HepG2-H cells (Fig. 1a). A colony formation assay was done to test whether metformin affected clonogenic potential, which is an important characteristic of tumor growth in vivo. As shown, more colony numbers were found in HepG2-H cells compared with HepG2 cell and metformin reduced the number of colonies in a dose-dependent manner (Fig. 1b). Furthermore, insufficient RFA induced an increase number of cell migration and invasion in HepG2 cells, which was also repressed by metformin in vitro (Fig. 1c).

Similar results were also found in SMMC7721 cells (Additional file 1: Figure S1).

\section{Metformin may regulate HCC cells proliferation, migration and invasion after insufficient RFA by promoting AMPK/ PTEN/Akt pathway}

Up-regulation of VEGF and PCNA and down-regulation of E-cadherin could be observed in HepG2-H cells at protein levels (Fig. 2). Treatment of cells with metformin increased E-cadherin expression, and decreased the PCNA and VEGF expression (Fig. 2). To explore the possible mechanism of metformin involved in the process of HCC cells after insufficient RFA, the AMPK/PTEN/Akt pathway was tested. Significantly increased expression of p-Akt and decreased expression of p-AMPK and PTEN were found in HepG2-H cells compared with HepG2 cells (Fig. 2). Furthermore, metformin decreased the expression of p-Akt and increased the expression of p-AMPK and PTEN in HepG2 and HepG2-H cells (Fig. 2).

Similar results were also found in SMMC7721 cells (Additional file 2: Figure S2). 


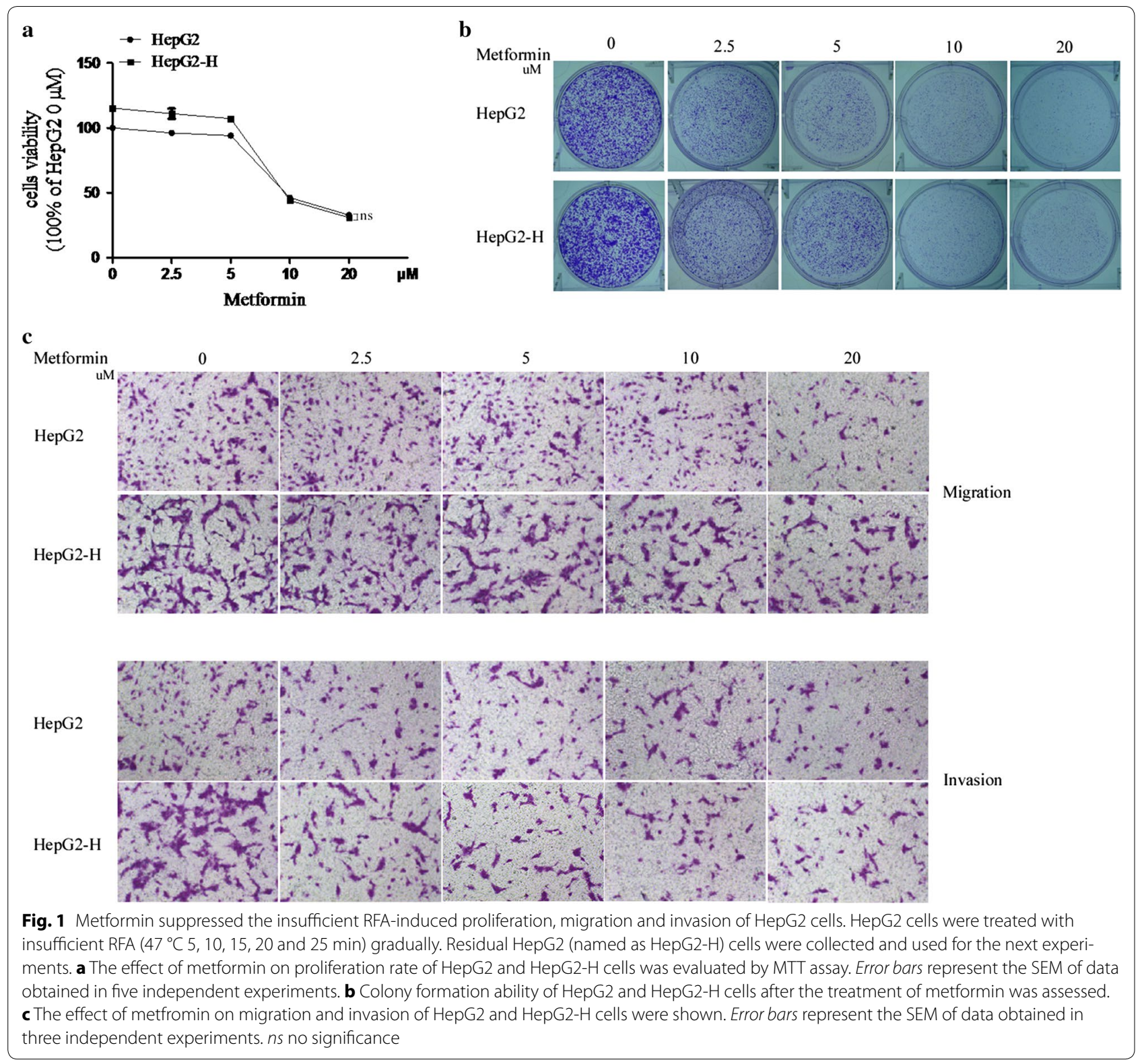

\section{Metformin ameliorated the process that insufficient RFA enhanced the growth of HCC cells in vivo}

In HepG2-H group, tumors grew more rapidly compared with HepG2 group, and metformin significantly inhibited the growth of HepG2 and HepG2-H tumors (Fig. 3a, b). Metformin ameliorated the difference of tumor growth between HepG2 and HepG2-H cells (Fig. 3a). Significant increases of cell proliferation were observed in HepG2$\mathrm{H}$ cells, and metfromin inhibited the process (Fig. 3c). Tumor microvessel density was analyzed using CD31. In HepG2-H group, tumor showed higher microvessel density compared with HepG2 group (Fig. 3c). In addition, the lower expression of E-cadherin was also found in HepG2-H cells. Metformin increased the expression of E-cadherin, and reduced tumor microvessel density in HepG2 and HepG2-H tumors (Fig. 3c).

\section{Metfromin did not cause apparent toxicity in nude mice bearing with tumor}

Metfromin had no significant effect on the mice body weight (Fig. 4a). Meanwhile, there were no apparent changes in liver, heart, kidney and lung in the mice (Fig. 4b).

\section{Discussion}

Diabetes is now considered an independent risk factor for HCC [24]. Even more, diabetes may be a promoter for the progression of HCC after insufficient RFA. Metformin is 


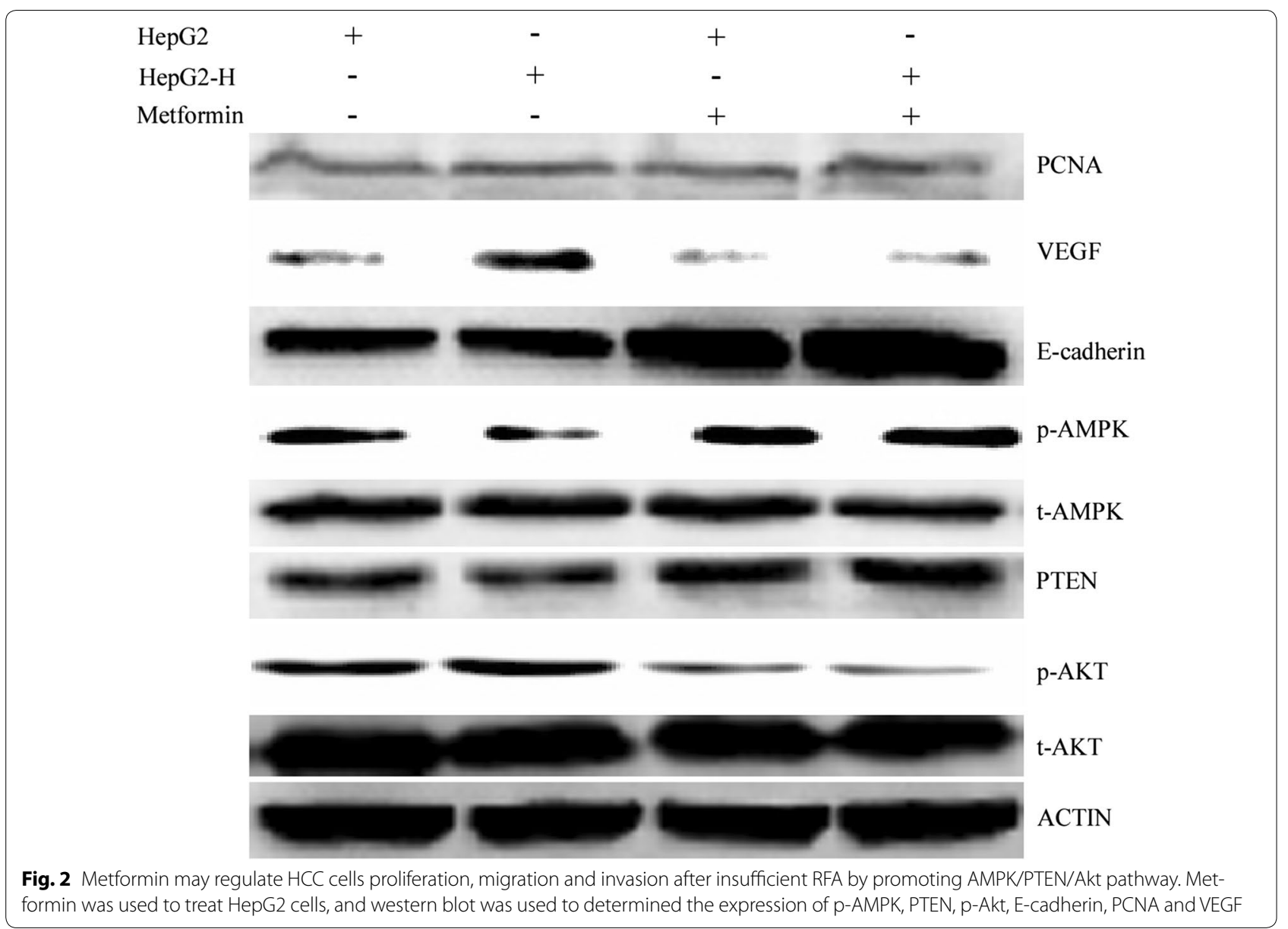

the first-line drug for T2DM patients. Hence, in the present study, we demonstrated that metformin significantly inhibited growth of HCC cells after insufficient RFA in vitro and vivo. Our study may highlight the potential application of metformin in HCC after RFA, especially in patients with diabetes.

Metformin exert a direct effect on cancer cells partially through the activation of AMPK. Furthermore, the mTOR/AMPK pathway is the main mechanism of action of metformin [25]. The mTOR pathway plays a major role in tumor initiation and progression because of its involvement in multiple carcinogenic events such as cell growth, proliferation, survival and metabolism as well as protein biosynthesis and angiogenesis by a hypoxia-inducible factor 1 and a VEGF (vascular endothelial growth factor) dependent manner [26]. mTOR can also be phosphorylated by phosphorylated p-Akt-serine (S) 473 to form p-mTOR-S2448, which positively regulates protein translation through the phosphorylation of its substrates, protein S6 kinase (p70S6K), and eukaryotic initiation factor 4E-binding protein 1 (4EBP1) [27]. Our previous study showed that HCC cells after insufficient RFA exhibited higher expression of p-Akt, which may play a key role in the EMT, and sorafenib suppressed the activity of p-Akt $[5,23]$. In the present study, metformin up-regulated the expression of p-AMPK and PTEN, down-regulated the expression of p-Akt in HCC cells after insufficient RFA, and further down-regulated the increased expression of PCNA and VEGF in HCC cells after insufficient RFA. Therefore, metformin may play the part in the process through AMPK/PTEN/Akt signaling pathway.

The extensive use of metformin with nearly 120 million prescriptions worldwide each year is due to its favourable benefit-risk profile [28]. The glucose-lowering effect induced by metformin is clinically associated with a superior safety profile related to less cardiac mortality and rare cases of lactic acidosis at therapeutic doses. Moreover, compared to other anti-diabetic agents, metformin does not induce hypoglycaemia or weight gain [29]. In our study, metformin showed no cytotoxic effect on mice and did not cause weight loss. Likewise, if metformin could be applied to prevent HCC recurrence and metastasis after RFA, its cost-effectiveness is superior to other targeted therapy or chemotherapy. 

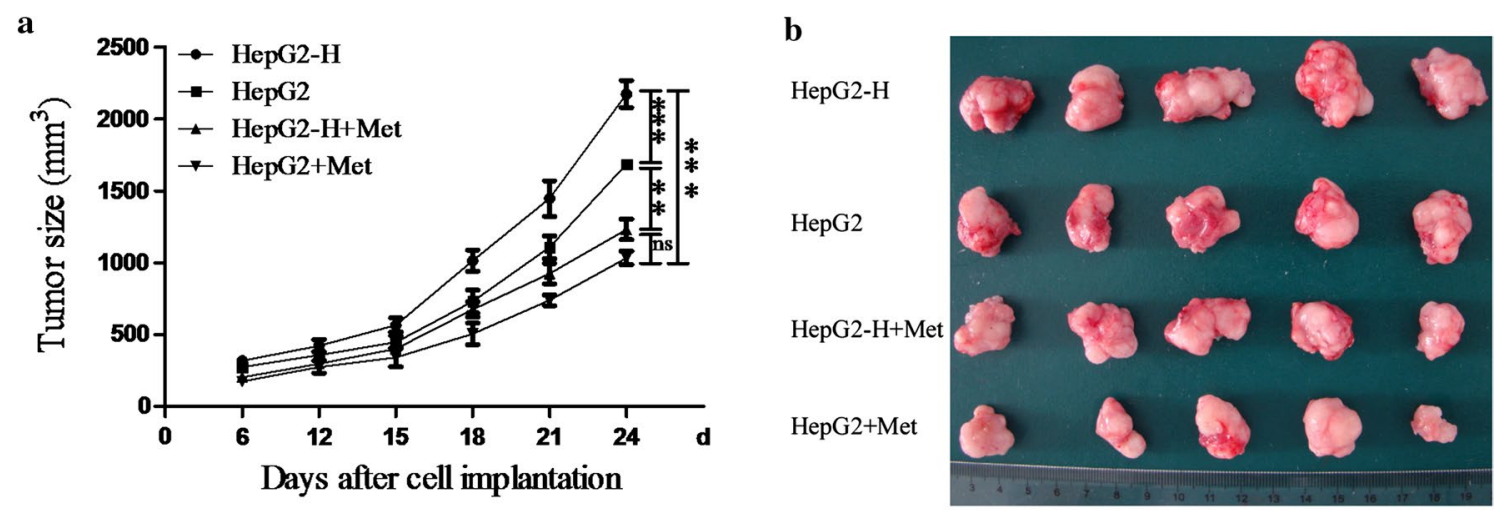

c HepG2-H
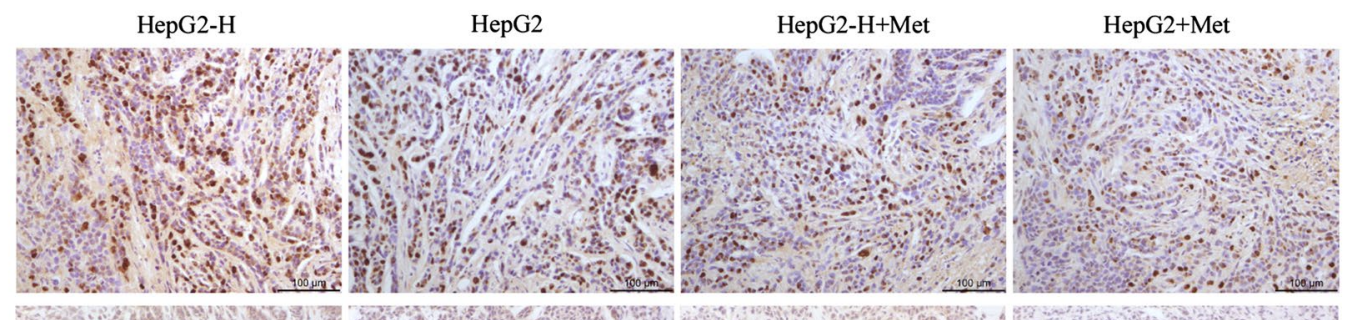

Ki-67
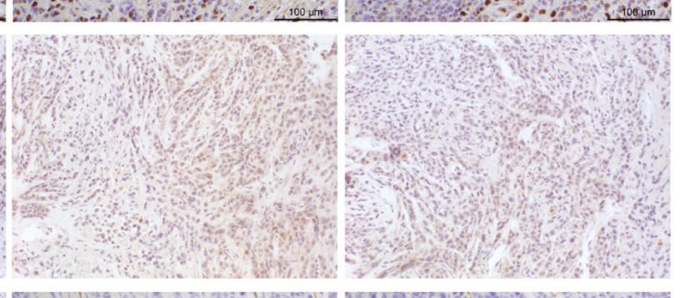

E-cadherin
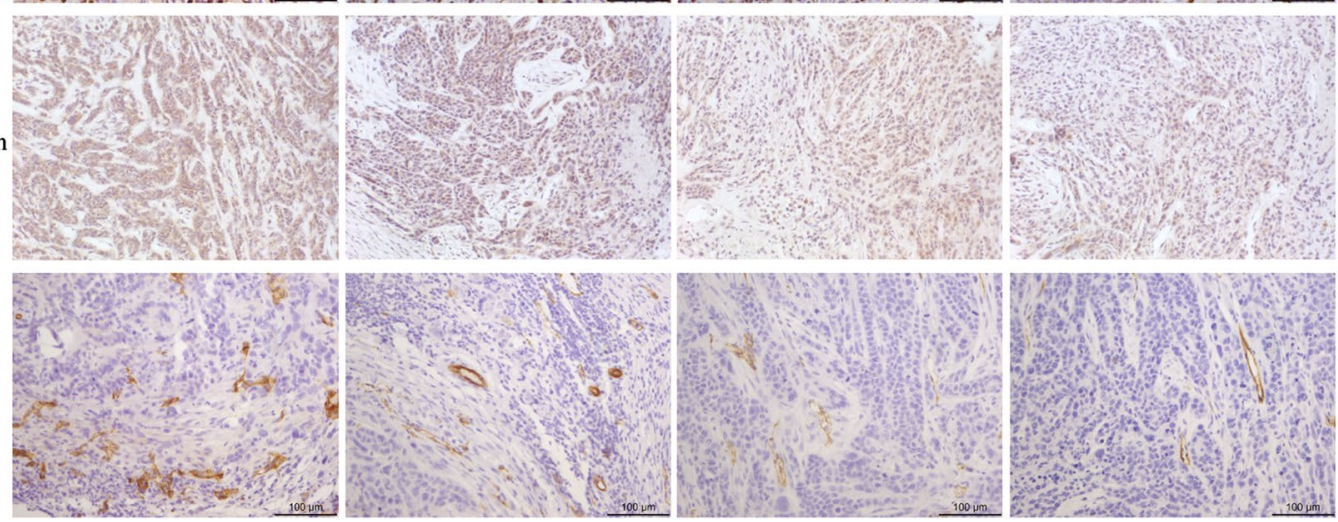

Fig. 3 Metformin ameliorated the process that insufficient RFA enhanced the growth of HCC cells in vivo. HepG2 and HepG2-H cells were injected subcutaneously into the upper right flank region of nude mice, treated with or without metformin, and tumor volume was measured. a Tumor volume was measured with a caliper rule every 3 days. Data were presented as the mean tumor volumes of mice. $\mathbf{b}$ Tumor size of the 24th day after cell implantation was displayed. cTumor sections were stained for Ki-67, E-cadherin, and CD31. Representative images of the immunohistochemistry assay were shown $(200 x)$

Many clinical trials demonstrated that metformin could reduce the incidence and recurrence of HCC. Donadon et al. demonstrated that metformin reduced the HCC risk in type 2 diabetic patients [30, 31]. Hassan et al. [32] also suggested that metformin reduced the incidence of HCC in type 2 diabetic patients in a hospital-based case-control study in the United States. Lee et al. [33] identified benefits of metformin for HCC prevention compared to other anti-diabetics, with a reduced risk of other tumors, pancreatic and colorectal cancer as well. Lai [34] showed metformin may reduce the risk of development HCC among diabetic patients. Chan et al. reported that the use of metformin significantly reduces the risk of $\mathrm{HCC}$ recurrence and improves the overall outcome of patients after liver resection if patients survive the initial 2 years [13]. Chen et al. also showed that metformin users among diabetic patients with HCC undergoing RFA had a favorable overall survival compared with patients without metformin treatment [35]. In our study, we showed that HCC cells after insufficient RFA exhibited larger tumor volume compared with HCC cells after control treatment, and metformin inhibited the growth of HCC cells and eliminated the difference of growth in HepG2-H and HepG2 cells. So metformin might be used to prevent the progression of HCC cells after insufficient RFA. However, the researches about the strategy 

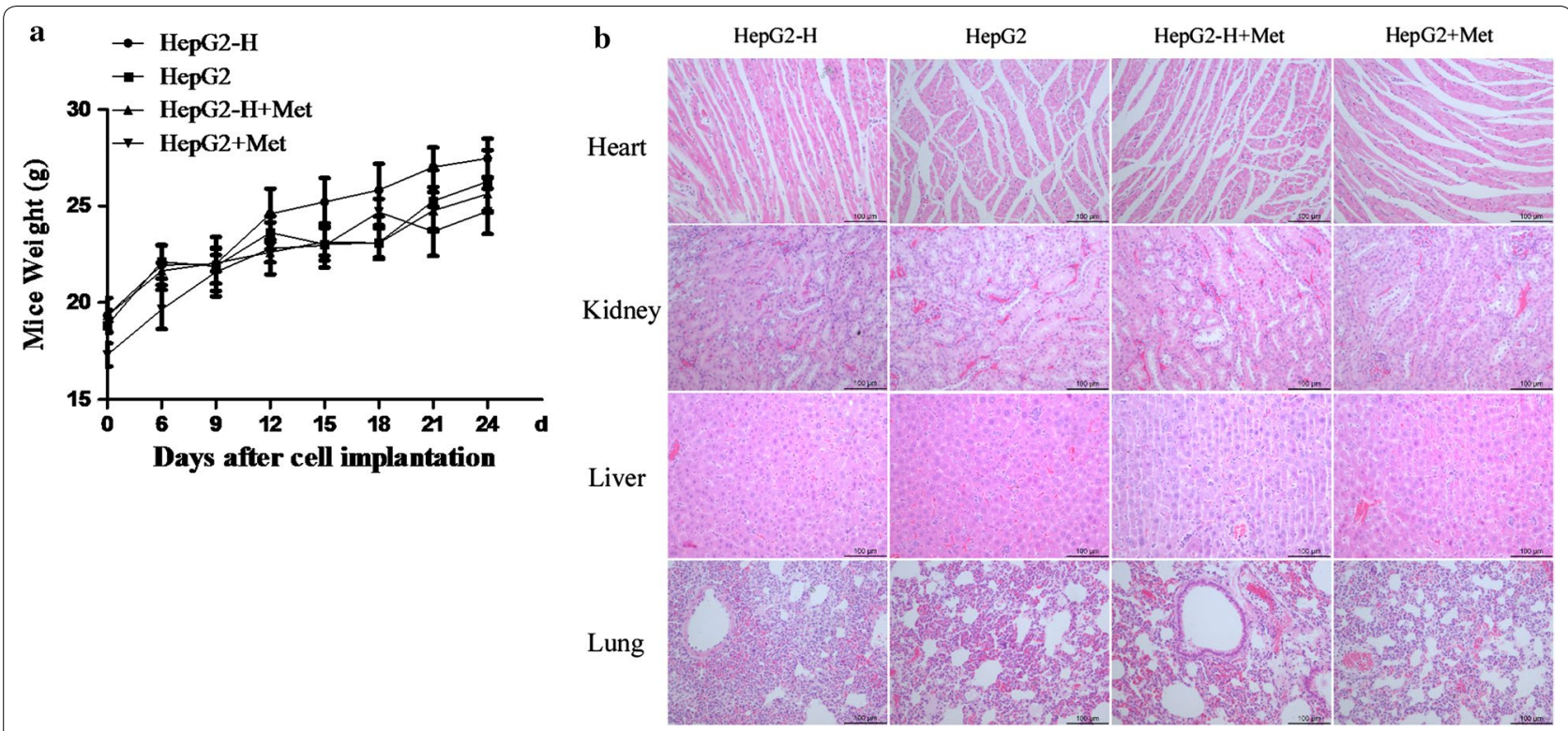

Fig. 4 Toxicity of metformin on nude mice bearing with tumor. a Mice weight was measured with a scale every 3 days. $\mathbf{b}$ Heart, lung, liver and kidney sections were stained with haematoxylin and eosin (HE). Representative images were shown (200x). ns no significance

to prevent the progression of HCC after RFA are limited. In the present study, we only provided the preliminary basis for the application of metformin to prevent the progression of HCC cells after RFA, and more mechanisms involved in the progression and clinical trials should be investigated in the future.

\section{Conclusions}

The study demonstrated that metformin inhibited the growth of HCC cells after insufficient RFA, and may be used to prevent the progression of HCC after RFA.

\section{Additional files}

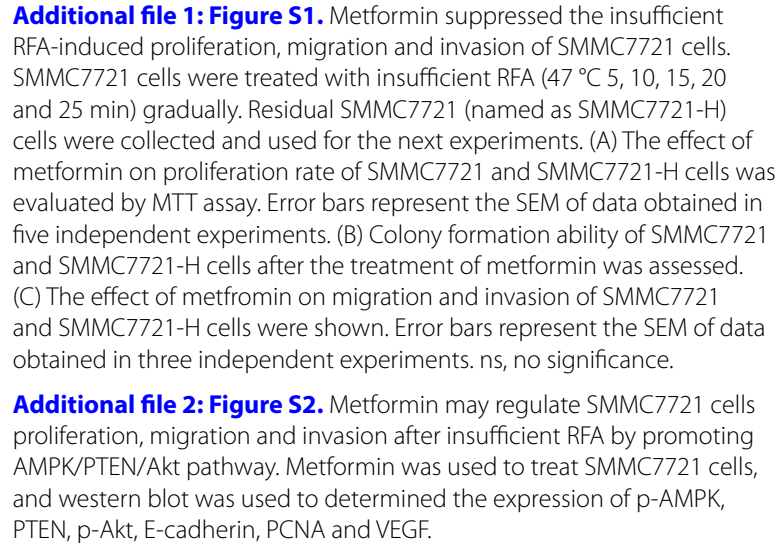

Additional file 1: Figure S1. Metformin suppressed the insufficient RFA-induced proliferation, migration and invasion of SMMC7721 cells. SMMC7721 cells were treated with insufficient RFA $\left(47^{\circ} \mathrm{C} 5,10,15,20\right.$ and 25 min) gradually. Residual SMMC7721 (named as SMMC7721-H) cells were collected and used for the next experiments. (A) The effect of metformin on proliferation rate of SMMC7721 and SMMC7721-H cells was evaluated by MTT assay. Error bars represent the SEM of data obtained in five independent experiments. (B) Colony formation ability of SMMC7721 and SMMC7721-H cells after the treatment of metformin was assessed. (C) The effect of metfromin on migration and invasion of SMMC7721 and SMMC7721-H cells were shown. Error bars represent the SEM of data obtained in three independent experiments. ns, no significance.

Additional file 2: Figure S2. Metformin may regulate SMMC7721 cells proliferation, migration and invasion after insufficient RFA by promoting AMPK/PTEN/Akt pathway. Metformin was used to treat SMMC7721 cells, and western blot was used to determined the expression of $\mathrm{p}-\mathrm{AMPK}$, PTEN, p-Akt, E-cadherin, PCNA and VEGF.

\section{Abbreviations}

RFA: radiofrequency ablation; HCC: hepatocellular carcinoma; DMEM: Dulbecco's modified Eagle medium; FBS: fetal bovine serum; HRP: horseradish peroxidase; OD: optical density; VEGF: vascular endothelial growth factor; T2DM: Type 2 Diabetes Mellitus.

\section{Authors' contributions}

QYZ carried out the experiments and drafted the manuscript. WBS conceived the study and coordination and helped to draft the manuscript. JK, SYD and WLX participated in the design of the study. All authors read and approved the final manuscript.

\section{Author details}

1 Department of Hepatobiliary Surgery, Beijing Chao-yang Hospital, Capital Medical University, Beijing 100043, China. ${ }^{2}$ Department of General Surgery, Affiliated Hospital of Chengde Medical University, Hebei 067000, China.

\section{Acknowledgements}

Not applicable.

\section{Competing interests}

The authors declare that they have no competing interests.

\section{Availability of data and materials}

The datasets used during the current study available from the corresponding author on reasonable request.

\section{Ethics approval and consent to participate}

All mice experiments were operated with the approval of Animal Care Committee of Capital Medical University according with the institutional guideline.

\section{Funding}

This work was supported by Grants from The National Natural Science Foundation of China (81502650 and 81572957).

\section{Publisher's Note}

Springer Nature remains neutral with regard to jurisdictional claims in published maps and institutional affiliations. 
Received: 17 December 2016 Accepted: 18 April 2017 Published online: 24 April 2017

\section{References}

1. Ferlay J, Soerjomataram I, Dikshit R, Eser S, Mathers C, Rebelo M, Parkin DM, Forman D, Bray F. Cancer incidence and mortality worldwide: sources, methods and major patterns in GLOBOCAN 2012. Int J Cancer. 2015;136(5):E359-86.

2. Grandhi MS, Kim AK, Ronnekleiv-Kelly SM, Kamel IR, Ghasebeh MA, Pawlik TM. Hepatocellular carcinoma: from diagnosis to treatment. Surg Oncol. 2016;25(2):74-85

3. Kang TW, Kim JM, Rhim H, Lee MW, Kim YS, Lim HK, Choi D, Song KD, Kwon CH, Joh JW, et al. Small hepatocellular carcinoma: radiofrequency ablation versus nonanatomic resection-propensity score analyses of long-term outcomes. Radiology. 2015;275(3):908-19.

4. Lee HY, Rhim H, Lee MW, Kim YS, Choi D, Park MJ, Kim YK, Kim SH, Lim HK. Early diffuse recurrence of hepatocellular carcinoma after percutaneous radiofrequency ablation: analysis of risk factors. Eur Radiol. 2013;23(1):190-7

5. Dong S, Kong J, Kong F, Kong J, Gao J, Ji L, Pan B, Chen L, Zheng L, Sun W. Sorafenib suppresses the epithelial-mesenchymal transition of hepatocellular carcinoma cells after insufficient radiofrequency ablation. BMC Cancer. 2015;15:939.

6. Xu M, Xie XH, Xie XY, Xu ZF, Liu GJ, Zheng YL, Huang GL, Wang W, Zheng SG, Lu MD. Sorafenib suppresses the rapid progress of hepatocellular carcinoma after insufficient radiofrequency ablation therapy: an experiment in vivo. Acta Radiol. 2013;54(2):199-204.

7. Llovet JM, Ricci S, Mazzaferro V, Hilgard P, Gane E, Blanc JF, de Oliveira AC, Santoro A, Raoul JL, Forner A, et al. Sorafenib in advanced hepatocellular carcinoma. N Engl J Med. 2008;359(4):378-90.

8. Evans JM, Donnelly LA, Emslie-Smith AM, Alessi DR, Morris AD. Metformin and reduced risk of cancer in diabetic patients. BMJ. 2005:330(7503):1304-5.

9. Ma SJ, Zheng YX, Zhou PC, Xiao YN, Tan HZ. Metformin use improves survival of diabetic liver cancer patients: systematic review and metaanalysis. Oncotarget. 2016;7(40):66202-11.

10. Quinn BJ, Kitagawa H, Memmott RM, Gills JJ, Dennis PA. Repositioning metformin for cancer prevention and treatment. Trends Endocrinol Metab TEM. 2013;24(9):469-80.

11. Zhang ZJ, Bi Y, Li S, Zhang Q, Zhao G, Guo Y, Song Q. Reduced risk of lung cancer with metformin therapy in diabetic patients: a systematic review and meta-analysis. Am J Epidemiol. 2014;180(1):11-4.

12. Daugan M, Dufay Wojcicki A, d'Hayer B, Boudy V. Metformin: an antidiabetic drug to fight cancer. Pharmacol Res. 2016;113(Pt A):675-85.

13. Chan KM, Kuo CF, Hsu JT, Chiou MJ, Wang YC, Wu TH, Lee CF, Wu TJ, Chou HS, Lee WC. Metformin confers risk reduction for developing hepatocellular carcinoma recurrence after liver resection. Liver Int Off J Int Assoc Study Liver. 2016;37(3):434-41.

14. Bhat M, Yanagiya A, Graber T, Razumilava N, Bronk S, Zammit D, Zhao Y, Zakaria C, Metrakos P, Pollak M, et al. Metformin requires 4E-BPs to induce apoptosis and repress translation of $\mathrm{MCl}-1$ in hepatocellular carcinoma cells. Oncotarget. 2016. doi:10.18632/oncotarget.10671.

15. Cauchy F, Mebarki M, Albuquerque M, Laouirem S, Rautou PE, Soubrane $\mathrm{O}$, Raymond E, Bedossa P, Paradis V. Anti-angiogenic effect of metformin in human liver carcinogenesis related to metabolic syndrome. Gut. 2015;64(9):1498-500.

16. Cauchy F, Mebarki M, Leporq B, Laouirem S, Albuquerque M, Lambert S, Bourgoin P, Soubrane O, van Beers B, Faivre S, et al. Strong antineoplastic effects of metformin in preclinical models of liver carcinogenesis. Clin Sci. 2016;131(1):27-36.

17. DePeralta DK, Wei L, Ghoshal S, Schmidt B, Lauwers GY, Lanuti M, Chung RT, Tanabe KK, Fuchs BC. Metformin prevents hepatocellular carcinoma development by suppressing hepatic progenitor cell activation in a rat model of cirrhosis Cancer. 2016:122(8):1216-27.
18. Kim EH, Kim MS, Furusawa Y, Uzawa A, Han S, Jung WG, Sai S. Metformin enhances the radiosensitivity of human liver cancer cells to gamma-rays and carbon ion beams. Oncotarget. 2016;7(49):80568-78.

19. Tian Y, Tang B, Wang C, Sun D, Zhang R, Luo N, Han Z, Liang R, Gao $Z$, Wang L. Metformin mediates resensitivity to 5-fluorouracil in hepatocellular carcinoma via the suppression of YAP. Oncotarget. 2016;7(29):46230-41.

20. Wu W, Yang JL, Wang YL, Wang H, Yao M, Wang L, Gu JJ, Cai Y, Shi Y, Yao DF. Reversal of multidrug resistance of hepatocellular carcinoma cells by metformin through inhibiting NF-kappaB gene transcription. World J Hepatol. 2016;8(23):985-93.

21. Yang $X$, Sun D, Tian Y, Ling S, Wang L. Metformin sensitizes hepatocellular carcinoma to arsenic trioxide-induced apoptosis by downregulating $\mathrm{Bcl} 2$ expression. Tumour Biol J Int Soc Oncodev Biol Med. 2015;36(4):2957-64.

22. You A, Cao M, Guo Z, Zuo B, Gao J, Zhou H, Li H, Cui Y, Fang F, Zhang W, et al. Metformin sensitizes sorafenib to inhibit postoperative recurrence and metastasis of hepatocellular carcinoma in orthotopic mouse models. J Hematol Oncol. 2016:9:20.

23. Dong S, Kong J, Kong F, Kong J, Gao J, Ke S, Wang S, Ding X, Sun W, Zheng L. Insufficient radiofrequency ablation promotes epithelial-mesenchymal transition of hepatocellular carcinoma cells through Akt and ERK signaling pathways. J Transl Med. 2013:11:273.

24. Fujita K, Iwama H, Miyoshi H, Tani J, Oura K, Tadokoro T, Sakamoto T, Nomura T, Morishita A, Yoneyama $\mathrm{H}$, et al. Diabetes mellitus and metformin in hepatocellular carcinoma. World J Gastroenterol. 2016;22(27):6100-13

25. Sinnett-Smith J, Kisfalvi K, Kui R, Rozengurt E. Metformin inhibition of mTORC1 activation, DNA synthesis and proliferation in pancreatic cancer cells: dependence on glucose concentration and role of AMPK. Biochem Biophys Res Commun. 2013;430(1):352-7.

26. Kim LC, Cook RS, Chen J. mTORC1 and mTORC2 in cancer and the tumor microenvironment. Oncogene. 2016;36(16):2191-201.

27. Bostner J, Karlsson E, Pandiyan MJ, Westman H, Skoog L, Fornander T, Nordenskjold B, Stal O. Activation of Akt, mTOR, and the estrogen receptor as a signature to predict tamoxifen treatment benefit. Breast Cancer Res Treat. 2013;137(2):397-406.

28. Ben Sahra I, Le Marchand-Brustel Y, Tanti JF, Bost F. Metformin in cancer therapy: a new perspective for an old antidiabetic drug? Mol Cancer Ther. 2010;9(5):1092-9.

29. Foretz $M$, Guigas B, Bertrand L, Pollak M, Viollet B. Metformin: from mechanisms of action to therapies. Cell Metab. 2014;20(6):953-66

30. Donadon V, Balbi M, Ghersetti M, Grazioli S, Perciaccante A, Della Valentina G, Gardenal R, Dal Mas M, Casarin P, Zanette G, et al. Antidiabetic therapy and increased risk of hepatocellular carcinoma in chronic liver disease. World J Gastroenterol. 2009;15(20):2506-11.

31. Donadon V, Balbi M, Mas MD, Casarin P, Zanette G. Metformin and reduced risk of hepatocellular carcinoma in diabetic patients with chronic liver disease. Liver Int off J Int Assoc Study Liver. 2010;30(5):750-8

32. Hassan MM, Curley SA, Li D, Kaseb A, Davila M, Abdalla EK, Javle M, Moghazy DM, Lozano RD, Abbruzzese JL, et al. Association of diabetes duration and diabetes treatment with the risk of hepatocellular carcinoma. Cancer. 2010;116(8):1938-46.

33. Lee MS, Hsu CC, Wahlqvist ML, Tsai HN, Chang YH, Huang YC. Type 2 diabetes increases and metformin reduces total, colorectal, liver and pancreatic cancer incidences in Taiwanese: a representative population prospective cohort study of 800,000 individuals. BMC Cancer. 2011;11:20.

34. Lai SW, Chen PC, Liao KF, Muo CH, Lin CC, Sung FC. Risk of hepatocellular carcinoma in diabetic patients and risk reduction associated with antidiabetic therapy: a population-based cohort study. Am J Gastroenterol. 2012;107(1):46-52.

35. Chen TM, Lin CC, Huang PT, Wen CF. Metformin associated with lower mortality in diabetic patients with early stage hepatocellular carcinoma after radiofrequency ablation. J Gastroenterol Hepatol. 2011;26(5):858-65. 